\title{
Performance on a differential reinforcement of low-rate schedule in neodecorticated rats and rats with hippocampal lesions
}

\author{
ELI J. JALDOW and DAVID A. OAKLEY \\ University College London, London, England
}

\begin{abstract}
Rats with total removal of neocortex (neodecorticates), hippocampectomized rats (hippocampals), and their controls were trained on a differential reinforcement of low-rate 12-sec (DRL12) schedule. With training, neodecorticates reduced the frequency of short interresponse times (IRTs) and increased the frequency of longer IRTs. They also significantly reduced the interresponse time per opportunity ratio for short IRTs and significantly increased the ratio in the period following reinforcement availability. Between-group differences on measures of IRT distribution, IRT per opportunity, and postreinforcement delay suggest separate contributions by neocortex and hippocampus to observed behavior on this task. Performance deficits in the lesioned groups are interpreted in terms of the associative power of the predictive lever increasing the pressure to respond in neodecorticates and the possible loss of place learning in both neodecorticates and hippocampals. In conjunction with previous work, these results indicate that temporal sensitivity in the rat is not destroyed by total neodecortication.
\end{abstract}

There is now little doubt that instrumental learning in rats and rabbits can take place in the absence of neocortex (e.g., Eames \& Oakley, 1985; Goldstein \& Oakley, 1987; Oakley, 1979a, 1980; Terry, Herbert, \& Oakley, 1989). In particular, more recent work using fixed-interval (FI) and fixed-time (FT) schedules (Jaldow, Oakley, \& Davey, $1989,1990)$ has raised the possibility that totally neodecorticated rats retain a functional timing mechanism.

FIs and FTs involve the spontaneous adjustment, with training, of the animal's own behavior to the parameters of the schedule. The differential reinforcement of lowrate (DRL) schedule requires the animal to adjust its response pattern to the temporal contingencies of the schedule to obtain reinforcement. More particularly, performance on the DRL is generally seen as reflecting temporal sensitivity or "timing" in animals (Blackman, 1979; Sidman, 1955). Typical findings are the development of low rates of responding inversely related to the length of the schedule (Zimmerman \& Schuster, 1962) and an increase in the frequency of interresponse times (IRTs) close in value to the DRL requirement, although response bursts (i.e., short IRTs) are also frequently observed. Collateral behaviors, which often accompany performance on DRL, appear to facilitate its acquisition and performance (e.g., Laties, Weiss, Clark, \& Reynolds, 1965; Laties, Weiss, \& Weiss, 1969). The DRL and FI schedules are two fun-

This work was supported by a Science and Engineering Research Council Studentship (Award No. 80311655) to E.J.J. We are grateful to $\mathrm{Mr}$. C. Cromarty for preparing the illustrations and to Roger Bunce for technical assistance. Correspondence should be addressed to David A. Oakley, Department of Psychology and Centre for Neuroscience, University College London, Gower Street, London WC1E 6BT, England. damental designs in the investigation of timing in animals (see Davey, 1981, and Richelle \& Lejeune, 1980, for fuller discussions).

The most consistent findings from animals with septal and hippocampal lesions on DRL are increased rates of responding and shorter IRTs lacking the normal mode of distribution (see O'Keefe \& Nadel, 1978; Richelle \& Lejeune, 1980). These findings can be interpreted as being due to an inability to use a place strategy as part of collateral activities (O'Keefe \& Nadel, 1978), impaired working memory (Meck, 1988; Olton, 1983), or proprioceptive-attentional deficits (Richelle \& Lejeune, 1980). The inclusion of hippocampals here was to see to what extent their behavior differed or was similar to that of the neodecorticate rats. Previous evidence suggests that these two structures make independent contributions to observed behavior on an FI40 (Jaldow, Oakley, \& Davey, 1989), Lashley's maze III (Eames \& Oakley, 1985), and behavioral flexibility tests (Terry \& Oakley, 1990) but not to tasks involving place learning (Sutherland, Kolb, \& Whishaw, 1982; Whishaw \& Kolb, 1984).

\section{METHOD}

\section{Subjects and Surgery}

There were 20 male hooded Lister rats, of which 5 underwent surgery to remove their neocortices (518D, 530D, 531D, 534D, 543D) and 5 were sham operated and served as controls ( $\mathrm{S}$ controls; 528S, 527S, 539S, 538S, 548S). Another 5 had their hippocampi removed $(512 \mathrm{H}, 529 \mathrm{H}, 533 \mathrm{H}, 537 \mathrm{H}, 536 \mathrm{H})$, and 5 more served as their cortical controls ( $C$ controls; 521C, 520C, 542C, 541C, 540C; see Table 1 for lesion sizes, weights, and postoperative recovery periods). Animals were housed individually with ad-lib access to water and maintained under artificial lighting between 8:00 a.m. and 8:00 p.m. Testing was carried out between 10:00 a.m. 
Table 1

Lesion Sizes, Body Weights, and Postoperative Intervals

\begin{tabular}{|c|c|c|c|c|c|}
\hline $\begin{array}{l}\text { Rat } \\
\text { No. }\end{array}$ & $\begin{array}{l}\text { Weight } \\
\text { at } \\
\text { Surgery* }\end{array}$ & $\begin{array}{c}\text { Percentag } \\
\text { Lesion } \dagger\end{array}$ & & $\begin{array}{c}\text { Weight } \\
\text { at Start } \\
\text { of Deprivation } \ddagger\end{array}$ & $\begin{array}{c}\text { Post } \\
\text { Operative } \\
\text { Interval } \$ \\
\end{array}$ \\
\hline \multicolumn{6}{|c|}{ Neodecorticates } \\
\hline $518 \mathrm{D}$ & 350 & 99.44 & & 356 & 16 \\
\hline 530D & 340 & 99.06 & & 352 & 15 \\
\hline $531 \mathrm{D}$ & 273 & 98.74 & & 317 & 16 \\
\hline 534D & 295 & 98.32 & & 334 & 15 \\
\hline 543D & 320 & 99.06 & & 333 & 14 \\
\hline \multicolumn{6}{|c|}{ S Controls } \\
\hline $528 \mathrm{~S}$ & 393 & - & & 413 & 15 \\
\hline $527 \mathrm{~S}$ & 318 & - & & 377 & 15 \\
\hline $538 S$ & 301 & - & & 355 & 15 \\
\hline $539 S$ & 302 & - & & 362 & 15 \\
\hline $548 S$ & 314 & - & & 354 & 14 \\
\hline \multicolumn{6}{|c|}{ Hippocampals } \\
\hline $512 \mathrm{H}$ & 307 & 75.03 & $(4.80)$ & 353 & 17 \\
\hline $529 \mathrm{H}$ & 318 & 81.74 & (3.07) & 350 & 15 \\
\hline $533 \mathrm{H}$ & 269 & 76.02 & $(6,07)$ & 335 & 16 \\
\hline $536 \mathrm{H}$ & 312 & 76.22 & $(4.32)$ & 377 & 20 \\
\hline $537 \mathrm{H}$ & 299 & - & - & 314 & 15 \\
\hline \multicolumn{6}{|c|}{ C Controls } \\
\hline $520 \mathrm{C}$ & 312 & - & - & 366 & 16 \\
\hline $521 \mathrm{C}$ & 345 & - & $(4.30)$ & 386 & 16 \\
\hline $540 \mathrm{C}$ & 305 & - & (4.27) & 371 & 19 \\
\hline $541 \mathrm{C}$ & 299 & - & $(5.01)$ & 368 & 14 \\
\hline $542 C$ & 286 & - & - & 354 & 14 \\
\hline
\end{tabular}

*Weight in grams. + For the hippocampals, the first figure is the percentage loss of hippocampus and the second figure in parentheses the percentage cortical loss. For the $\mathrm{C}$ controls, the figure in parentheses shows the percentage cortical loss. (One hippocampal and two $\mathrm{C}$ control brains were damaged during histological processing.) $\ddagger$ Mean weight in grams calculated from three days prior to taking animals off their ad-lib diet. $\$$ Interval in weeks between surgery and the first day of testing.

and 7:00 p.m. All animals were experimentally naive at the start of training.

Neodecortication was achieved by pial stripping, which devascularized the underlying hemispheres (see Oakley, 1979b). The sham-operated animals received two trephine holes $(5-\mathrm{mm}$ diam), one in each hemisphere, over the parietal cortex. Hippocampal lesioning was carried out by standard aspiration, commencing with the dorsal hippocampus, after the bilateral removal of the overlying parietal cortex. Cortical controls serving as controls for the hippocampals had a similar amount of parietal cortical tissue removed from the same locations. All surgery was carried out bilaterally in one stage under pentobarbital sodium (Sagatal) anesthesia.

For approximately 10 to 14 days after surgery, all animals were given a vitamin supplement in their drinking water (Vidaylin, Abbott Labs, Kent) and were given a moist, mashed diet consisting of a mixture of powdered laboratory chow, condensed sweetened milk, and water. Since neodecorticates tended to be aphagic and adipsic, they were hand-fed and also had their drinking water administered by hand during this period (see Whishaw, Schallert, \& Kolb, 1981).

\section{Apparatus}

All testing was carried out in a Skinner box fitted with two Perspex levers that could be lit from behind by a small light bulb ( $24 \mathrm{~V}$, $2.81 \mathrm{~W}$ ). The levers were situated at either side of the food tray. The box was illuminated throughout each session by a houselight ( $24 \mathrm{~V}, 40 \mathrm{~mA}$ ) close to the ceiling and was ventilated with an extractor fan. There was no tray door; two photo cells were located at the entrance to the food tray to record tray entries (see Jaldow,
Oakley, \& Davey, 1990). Reinforcement was delivered with a standard automated dipper that consisted of an arm with a small cup at the end. The reinforcer consisted of diluted condensed sweetened skimmed milk (Fussell's), the ratio of milk to water being 1:3. Each operation of the dipper (i.e., reinforcement) delivered $0.1 \mathrm{ml}$ of the milk into the food tray from a supply of diluted milk stored in a metal reservoir $(8.50 \times 5.75 \times 2.50 \mathrm{~cm}$ high) situated below the food tray. Contact with the dipper arm was recorded with a drinkometer circuit. The Skinner box was linked to an ATOM computer for both program control and data storage.

\section{Procedure}

Magazine training. All animals were reduced to about $90 \%$ of their free-feeding body weights over a 3-day period. They were then individually placed in the Skinner box, with one of the two levers lit from behind. It was decided at random with which of the two levers (right or left) a particular animal and its control were to be trained. The same lever was then illuminated on all subsequent sessions. A small plastic cup ( $1 \mathrm{~cm}$ high, $2 \mathrm{~cm}$ diam) filled with milk was placed in front of the food tray. The animal was then left in the Skinner box for $\mathbf{3 0} \mathrm{min}$ (all subsequent magazine training and leverpress-acquisition sessions, unless otherwise stated, were approximately $30 \mathrm{~min}$ long). The cup was periodically refilled when the animal had consumed the milk. On the next session (provided the animal had taken the milk on the previous session), the cup was placed inside the food tray. By the fourth session, all animals were reliably taking the milk from the cup inside the food tray.

Instead of being given the milk in the plastic cup, animals were then given the milk by means of the mechanical dipper arm. The arm was activated manually and stayed up (in the tray) until the animal had taken the milk. When the arm was activated, the food tray also lit up. All animals learned to take the milk from the arm during the course of one session.

Leverpress acquisition. Successive approximation was used to shape the animal towards pressing the lit lever. The arm was again activated manually to deliver reinforcement and stayed up for approximately $5 \mathrm{sec}$ after the animal had started to lick up the milk. Once the animal had learned to press the lever, it was given one 15-min session of continuous reinforcement (i.e., fixed ratio 1).

Differential reinforcement of low-rate (DRL) training. Animals were maintained at approximately $90 \%$ of their free-feeding body weights. All animals were run for 60 daily sessions, each session lasting $30 \mathrm{~min}$. A session commenced with the rat's being weighed and then placed into the Skinner box. The program was started, and the appropriate lever light, as well as the houselight, came on. Any response the animal made to the lit lever was reinforced if the animal had not pressed that lever during the immediately preceding $12 \mathrm{sec}$. If the animal did press the lit lever during those $12 \mathrm{sec}$, the timer reset and a new count of $12 \mathrm{sec}$ was started. When reinforcement was obtained, the food tray lit up and the dipper arm bearing the milk came up into the tray and stayed there for $5 \mathrm{sec}$ after the animal had made contact. When the $5 \mathrm{sec}$ were up, the arm descended again, the tray light was turned off, and a new count of $12 \mathrm{sec}$ started. The period between the offset of the tray light and the delivery of the next reinforcer was considered a single trial.

\section{Histology}

After completion of testing, the animals were given a lethal dose of sodium pentobarbitone (Sagatal) intraperitoneally and were perfused with a saline solution followed by a $10 \%$ formol-saline solution. Brains were removed and embedded in paraffin wax. Coronal sections were cut at $14-\mu \mathrm{m}$ thickness, and every 7 th section was stained with cresyl violet and mounted onto glass.

The extent of the lesion was calculated by first drawing from the prepared slides onto drawings of nine standard coronal sections. For decorticates, the percentage cortical loss was then calculated by perimetry. For hippocampals, the damage was assessed by shad- 
ing in the lesion area on each of the coronal sections and then by using a VP1 12 target-scanning unit (supplied by HVS Image Analysis, Kingston, England) linked to a BBC microcomputer to calculate the percentage loss.

\section{Statistical Analysis}

Data were analyzed, unless otherwise stated, by a two-way analysis of variance (ANOVA) with factor 1 (lesions) having four levels (four groups) and factor 2 (sessions) having two levels (first four sessions vs. the last four sessions). Significant interactions were further analyzed by using the simple effects method described by Howell (1982). Where appropriate, differences between means were further analyzed with a post hoc Tukey test (see Cohen $\&$ Holliday, 1983).

For the analysis of the interresponse time as a function of opportunity (IRT/Op) a three-way ANOVA was used. Factor 1 had four levels; factor 2 had two levels, as above. Factor 3 (bins) had two levels: level 1 , the first three, 2 -sec bins $(0-6 \mathrm{sec})$ after a leverpress or the start of a trial, and level 2 , the first three bins after reinforcement became available $(12-18 \mathrm{sec})$. It was reasoned that any significant changes with training would clearly become apparent by a reduction of IRTs falling in the early bins and an increase in IRTs in the bins immediately following availability of reinforcement.

All statistical tests were carried out on a BBC microcomputer, with programs in BASIC either taken from Cohen and Holliday (1983) or made in-house. Unless otherwise stated, all tests were carried out on the first and last four sessions of training, and significance was evaluated with reference to a two-tailed test, where appropriate, at the $5 \%$ level. Only significant values are presented.

\section{RESULTS}

\section{Histology}

The mean (and standard deviation, $S D$ ) cortical loss for the five neodecorticates was $98.92 \%$ ( $S D 0.42$ ). For the hippocampals, the mean hippocampal loss was $77.25 \%$ ( $S D$ 3.04) and the mean cortical loss was $4.56 \%$ ( $S D$ 1.24). For the $C$ controls, the mean cortical loss was $4.53 \%$ (SD 0.42). Individual lesion sizes, body weights, and postoperative intervals are shown in Table 1 . Representative standard coronal sections showing lesion location in neodecorticates, hippocampals, and cortical controls are shown in Figure 1. There was no significant difference in weights either at surgery or start of deprivation; neither was there a significant difference in postoperative intervals between the four groups.

\section{Leverpress Training}

The mean number of training sessions required to teach each group to press the lever reliably were: neodecorticates, 4.00 (SD 0); S controls, 5.40 (SD 0.89); hippocampals, 4.80 (SD 0.84); and C controls, 5.20 (SD 1.30). There was no significant difference between the four groups in the number of sessions required to master the leverpress.

\section{DRL}

Number of responses per session. This is a relatively simple measure of efficiency. With training one would expect to see a reduction in the number of responses per session, as this is part of the requirement of the sched-

\section{NEODECORTICATE \\ 543 D $\quad 99.06 \%$}
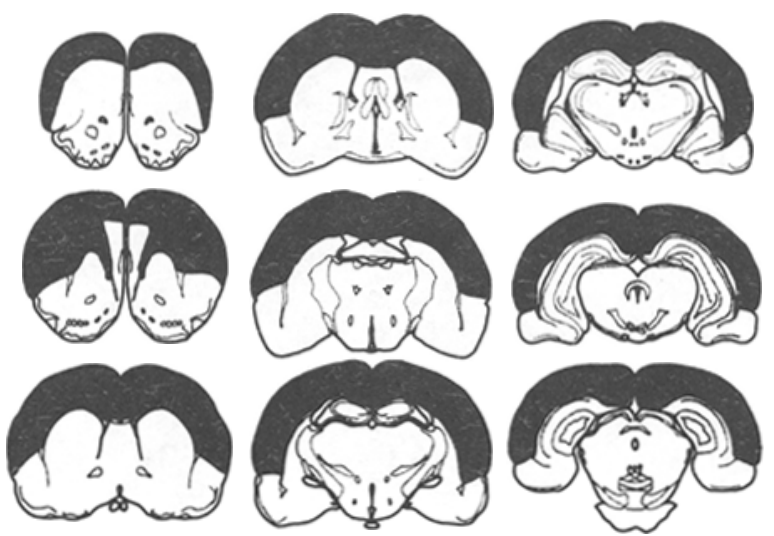

HIPPOCAMPAL

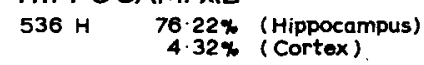
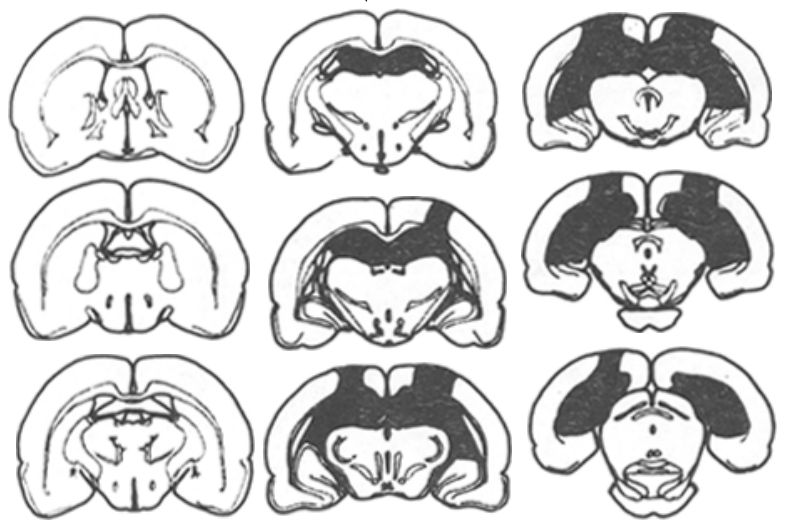

CORTICAL CONTROL
$521 \mathrm{C}$
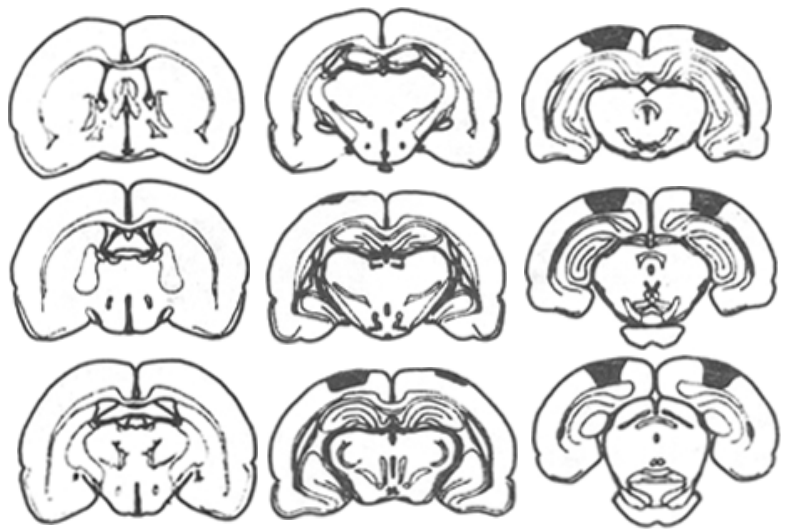

Figure 1. Representative coronal sections for one neodecorticate (543D), one hippocampal (536H), and one cortical control (521C) showing, in black, cortical and hippocampal loss. The percentage loss of the target tissue is shown for each animal. 
ule. The mean number of responses at the start and end of training were, respectively: neodecorticates, 417.60 (SD 79.04) and 250.00 (SD 102.48); S controls, 339.45 (SD 56.59) and 126.25 (SD 8.19); hippocampals, 523.88 (SD 111.38) and 203.25 (SD 53.14); and C controls, 332.77 ( $S D$ 49.62) and 130.45 ( $S D$ 6.02).

At the start of training, there was a significant difference between the four groups $[F(3,25)=8.41, p<.001]$, which was due to hippocampals' having significantly more responses per session than either control group [Tukey, $p<.01]$. At the end of training, the difference between groups was also significant $[F(3,25)=3.80, p<.025]$, but this time it was due to neodecorticates' having significantly more responses than the $\mathrm{S}$ controls [Tukey, $p<$ .025]. With training, all groups significantly reduced their responses per session [neodecorticates, $F(1,16)=30.13$, $p<.001$; S controls, $F(1,16)=48.76, p<.001$; hippocampals, $F(1,16)=110.28, p<.001$; and $C$ controls, $F(1,16)=43.91, p<.001]$.

Number of reinforcements. Another relatively simple measure of an animal's success on the DRL schedule is the mean number of reinforcements obtained in the training sessions. This number was calculated for each group on the 60 training sessions and is shown in Figure 2.

There was a significant difference between groups at the end of training $[F(3,32)=17.08, p<.001]$, with neodecorticates and hippocampals having significantly fewer reinforcements than either control group [Tukey, $p<.01]$. There was a significant increase in the number of reinforcements between the first and last four sessions for $S$ controls $[F(1,16)=43.67, p<.001]$, hippocampals $[F(1,16)=9.58, p<.01]$, and $C$ controls $[F(1,16)=35.11, p<.001]$ but not neodecorticates; however, for the neodecorticates, the correlation between increasing session number and mean number of reinforcements obtained was highly significant $[t(58)=9.17$, $p<.001]$.

Interresponse time distribution. A low number of reinforcements obtained per session does not necessarily indicate that an animal has not learned anything about the temporal requirements of the schedule. By looking at changes, if any, in the length and frequency of IRTs as a function of training, a clearer picture of an animal's temporal sensitivities may be obtained. Accordingly, the frequency of IRT durations, split into successive 2-sec bins, was calculated as a percentage of the total number of IRTs for each animal and then for the group. All IRTs over $24 \mathrm{sec}$ long were placed into the last bin (see Figure 3).

With training, all animals showed a shift in IRT distribution. The two control groups peaked in the bin immediately following $12 \mathrm{sec}$ (the critical value), whereas the hippocampals peaked in the 10-12-sec bin and the decor-

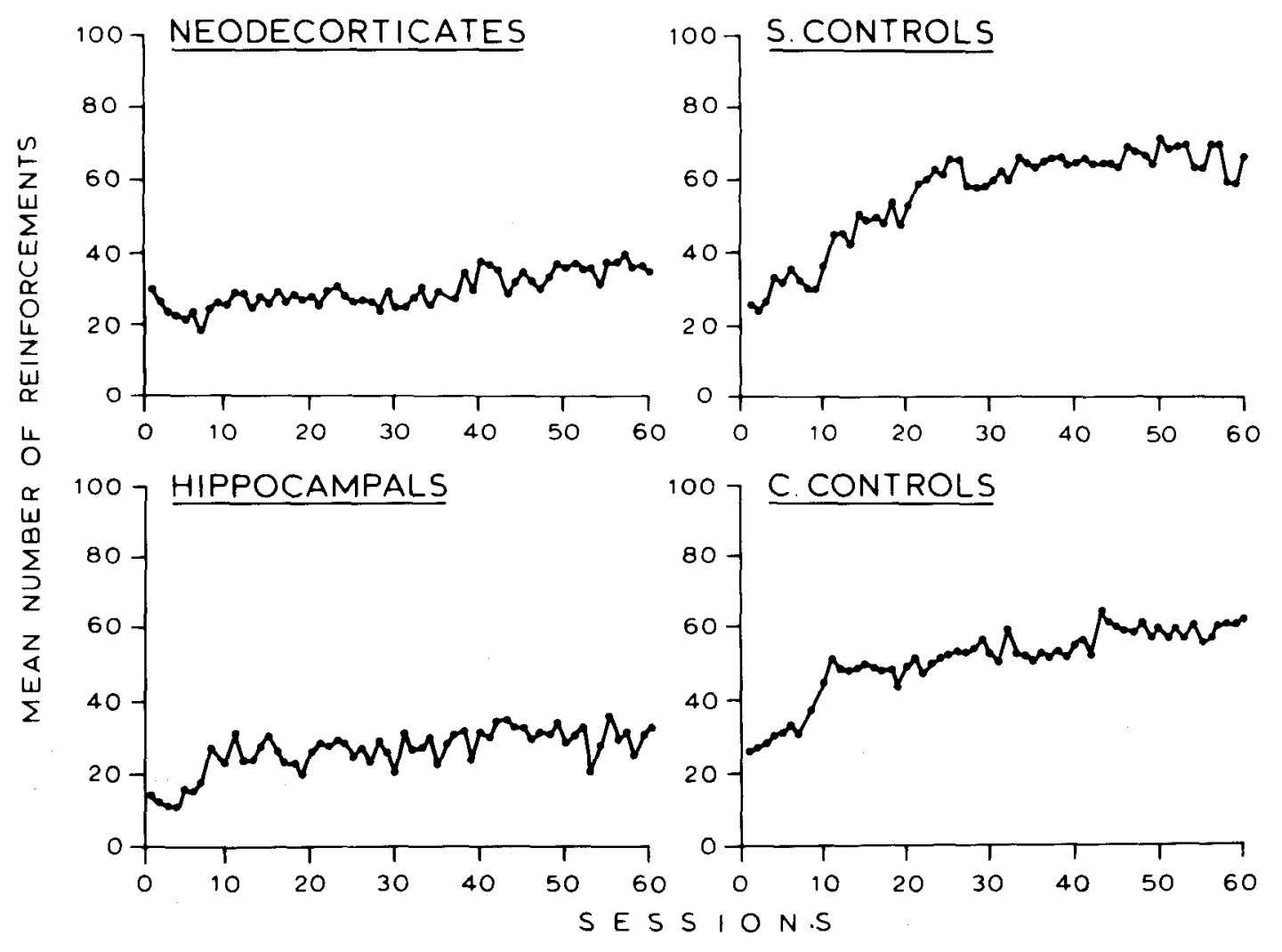

Figure 2. Mean number of reinforcements (trials) on the 60 sessions of training on differential reinforcement of lowrate $12 \sec$ (DRL12) for each group. 
NEODECORTICATES

S. CONTROLS
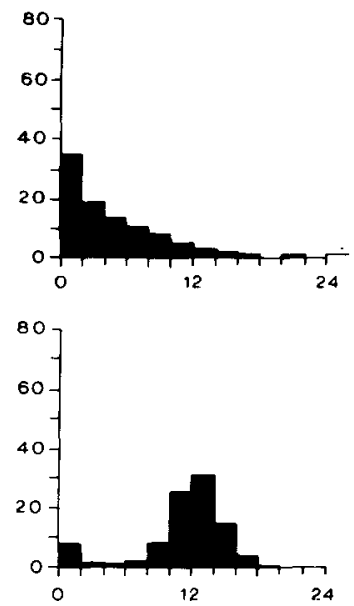

SE C O N D S
HIPPOCAMPALS
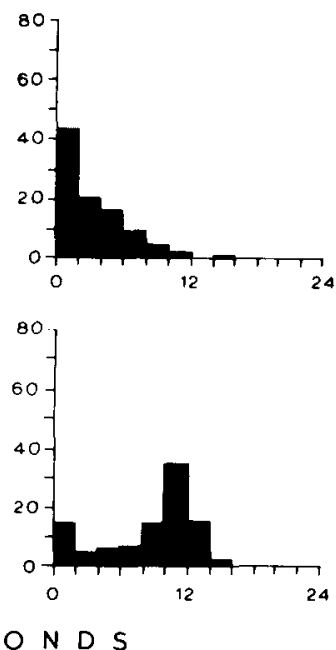

C. CONTROLS

SESSION

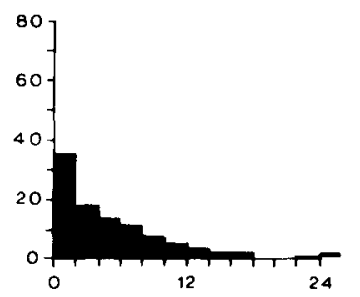

$1-4$
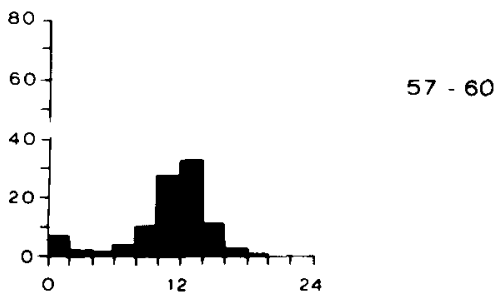

Figure 3. Mean frequency distribution of interresponse times (IRTs) as a percentage of total frequency, in 13 consecutive 2 -sec bins, on the first (top) and last (bottom) four sessions of training for each group. The last bin contains the frequency of all IRTs above 24 sec. (Note that the distribution includes IRTs initiated by exteroceptive and interoceptive signals.)

ticates peaked even earlier (apart from the very first bin) around the 6-8-sec bin. The hippocampals had significantly fewer IRTs as a percentage of total IRTs in bin $12-14$ sec than did both control groups $[F(2,20)=9.25$, $p<.01]$. All groups, even at the end of training, still had relatively high numbers of IRTs in the very first bin, perhaps indicative of response bursts after unsuccessful IRTs (see Davey, 1981).

Interresponse time per opportunity (IRT/Op). Anger (1956) has pointed out that simply looking at the IRT frequency distribution ignores the fact that by responding early in the interval (i.e., emitting short IRTs), the animai effectively reduces the opportunity of having long IRTs. The frequency of IRTs falling into a particular bin is, therefore, in part dependent on how often the animal had the chance (i.e., opportunity) of responding in that bin (see also Blackman, 1979; Richelle \& Lejeune, 1980). An analysis of the IRT/Op was therefore carried out. The frequency of IRTs falling into a particular bin was divided by the number of IRTs falling into that bin plus the frequency of all IRTs falling into subsequent bins. The denominator reflects the number of times a particular bin was "presented" to an animal; the numerator reflects the number of times the animal responded in that bin. The last bin, which includes all IRTs over $24 \mathrm{sec}$, will of necessity always have a value of 1.00 (provided that there were IRTs in excess of $24 \mathrm{sec}$ ) and is therefore not presented (see Figure 4). As can be seen, all animals showed a reduction with training of IRTs/Op on the early bins and an increase in IRTs/Op following the critical 12-sec duration.

With the focus on the first three bins (i.e., IRTs up to $6 \mathrm{sec}$ ), the difference between groups was significant $[F(3,16)=9.52, p<.001]$, with neodecorticates over- all having significantly more IRTs/Op than both control groups [Tukey, $p<.05$ ]. With training, however, all groups showed a significant decrease in IRTs/Op in the first three bins $[F(1,16)=439.76, p<.001]$.

On the first three bins after availability of reinforcement (i.e., IRTs between 12 and $18 \mathrm{sec}$ ), the difference between groups was significant only at the end of training $[F(3,28)=20.64, p<.001]$, with neodecorticates having significantly fewer IRTs/Op in these bins than any of the other groups (Tukey, $p<.01$ ). With training, though, each group significantly increased their IRTs/Op in the three bins following reinforcement [neodecorticates, $F(1,16)=28.83, p<.001 ; S$ controls, $F(1,16)=103.25$, $p<.001$; hippocampals, $F(1,16)=165.76, p<.001$; and $C$ controls, $F(1,16)=133.33, p<.001$ ] .

Percentage of reinforced IRTs initiated by exteroceptive signals. A new count of $12 \mathrm{sec}$ could be started either by an animal pressing the lit lever before $12 \mathrm{sec}$ had passed since the last press to that lever (interoceptive signal) or after the $5 \mathrm{sec}$ allowed for consumption of the reinforcer (exteroceptive signal). Given neodecorticates' possible exterosensory deficits, they might be expected to show more internally guided successful IRTs, and hippocampals-on the assumption that they may have difficulty with proprioceptive feedback (Richelle \& Lejeune, 1980)-might be expected to show more externally guided successful IRTs, as noted in the introduction. Accordingly, all successful responses preceded by the exteroceptive signals of the tray light going off and the dipper going down again were divided by the total number of all successful responses in order to obtain a percentage score.

The mean scores at the start and end of training were, respectively: neodecorticates, $32 \%(S D 13)$ and $32 \%$ (SD 
NEODECORTICATES

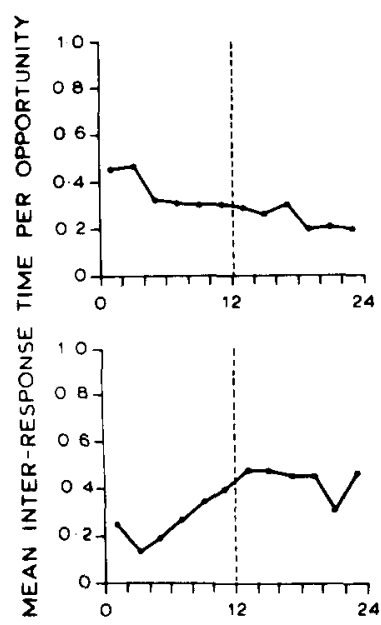

S. CONTROLS
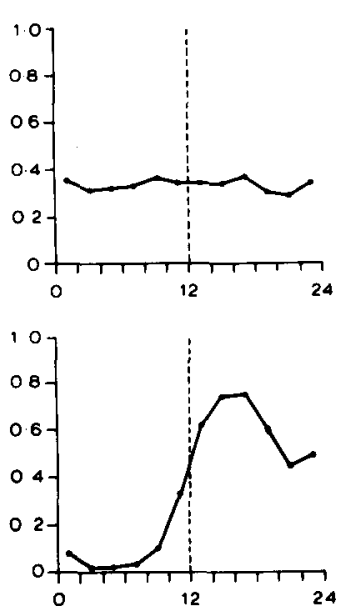

HIPPOCAMPALS
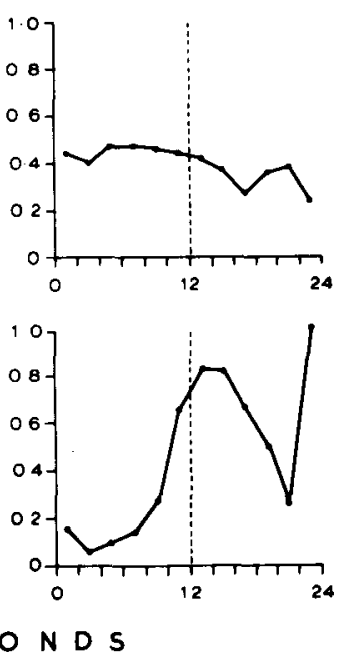

C.CONTROLS

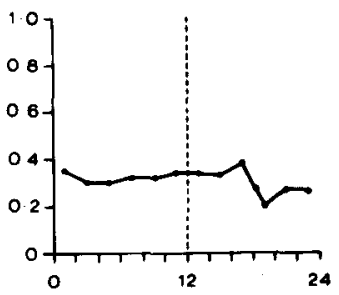

$1-4$

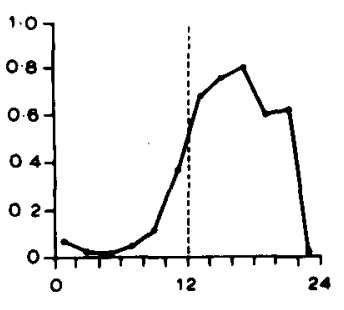

SESSIONS

$S E C O N D S$

Figure 4. Mean interresponse time per opportunity (IRT/Op), in successive 2-sec bins, on the first (top) and last (bottom) four sessions of training for each group. The vertical line indicates the point in time after which reinforcement was available if the animal pressed the lever. Where applicable, all IRTs above $24 \mathrm{sec}$ were treated as falling into one large bin with an associated probability of 1.00 and are therefore not presented.

19); $S$ controls, 12\% (SD 5) and 60\% (SD 9); hippocampals, $7 \%(S D 8)$ and $16 \%(S D 12)$; and $C$ controls, $15 \%(S D 13)$ and $55 \%(S D 11)$. The difference between groups at the start of training was significant $[F(3,31)=$ $4.10, p<.025$ ], which was due to the neodecorticates' having significantly higher percentages than the hippocampals [Tukey, $p<.05$ ]. At the end of training, the difference between groups was also significant $[F(3,31)=$ $14.95, p<.001]$, which was due to neodecorticates' and hippocampals' having significantly lower percentage scores than either control group [Tukey; $\mathrm{S}$ controls, $p<$ .01 ; C controls, $p<.05$; hippocampals, $p<.01$ in both cases].

With training, both control groups significantly increased their percentages [S controls, $F(1,16)=33.80$, $p<.001 ; \mathrm{C}$ controls, $F(1,16)=24.94, p<.001]$.

Thus, at the end of training (unlike the beginning), more than half of the reinforced IRTs for the controls were initiated by exteroceptive signals. For the lesioned animals, no significant change took place; both groups continued to emit most of their reinforced responses after an unsuccessful response (interoceptive signal).

Postreinforcement delay. The postreinforcement delay was the elapsed time between the reinforced lever response and the animal starting to lick the milk. The mean values at the start and end of training were, respectively: neodecorticates, 1.29 (SD 0.39) and 0.94 (SD 0.25); $S$ controls, 0.33 (SD 0.08) and 0.24 (SD 0.05); hippocampals, $0.38(S D 0.12)$ and $0.36(S D 0.07)$; and $C$ controls, 0.38 (SD 0.05) and 0.28 (SD 0.11).

The difference between groups was significant $[F(3,16)=$ $38.58, p<.001]$. Post hoc comparisons showed that neodecorticates had significantly higher PRDs than any of the other groups [Tukey, $p<.01$ in each case]. The difference between sessions was also significant $[F(1,16)=$ $8.45, p<.025]$, all groups significantly reducing their PRDs with training.

\section{Behavioral Observations}

Detailed behavioral observations were made of all animals during the last four sessions of training. Observations lasted approximately $6 \mathrm{~min}$. The procedure was to observe the animals at roughly the same time during each recorded session.

The observations were analyzed in terms of segments, that is, activities that occurred between one contingent leverpress and the next one (Figure 5). (The segments that do not start with a leverpress will have been emitted after reinforcement.) In order to highlight the group differences, the data presented are from the four animals (one from each group) that had the largest number of trials (i.e., reinforcements) on the last four sessions of training.

In obtaining reinforcement, both of the control animals shown in Figure 5 developed, with training, one dominant, relatively short segment containing three elements (in both cases, this consisted of pressing the reinforcing lever or obtaining reinforcement, moving to the other side of the box, and contacting the other lever and then gnawing or biting at the light bulb cover above it). The two lesioned animals, on the other hand, had more varied and longer segments ranging over the entire area of the box. This finding generally holds for all of the animals in each of the groups except that some $\mathrm{C}$ controls also showed development of dominant longer segments. The results suggest that the control groups were able to successfully bridge the IRT by engaging in a few behaviors at a par- 


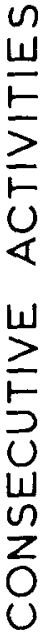
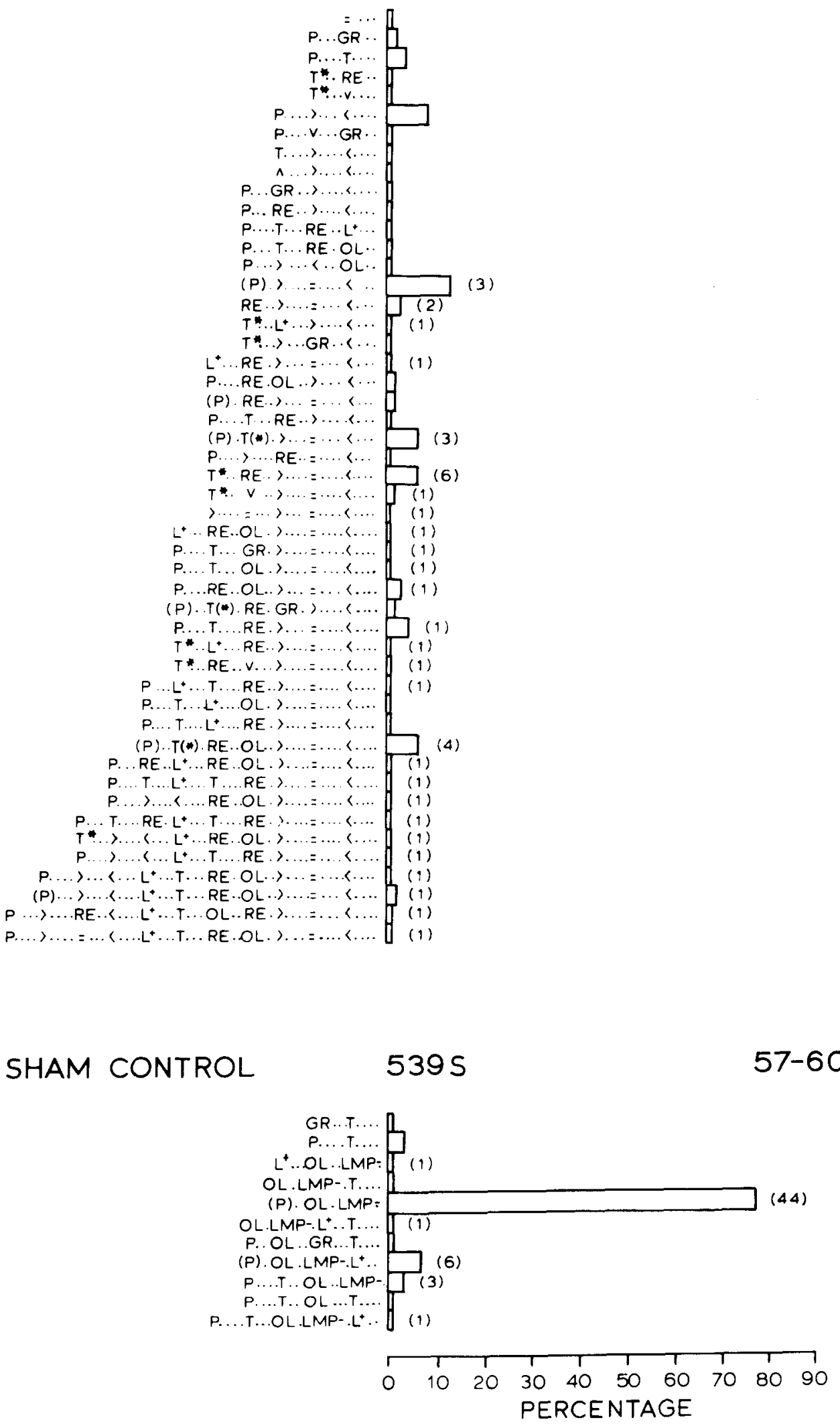


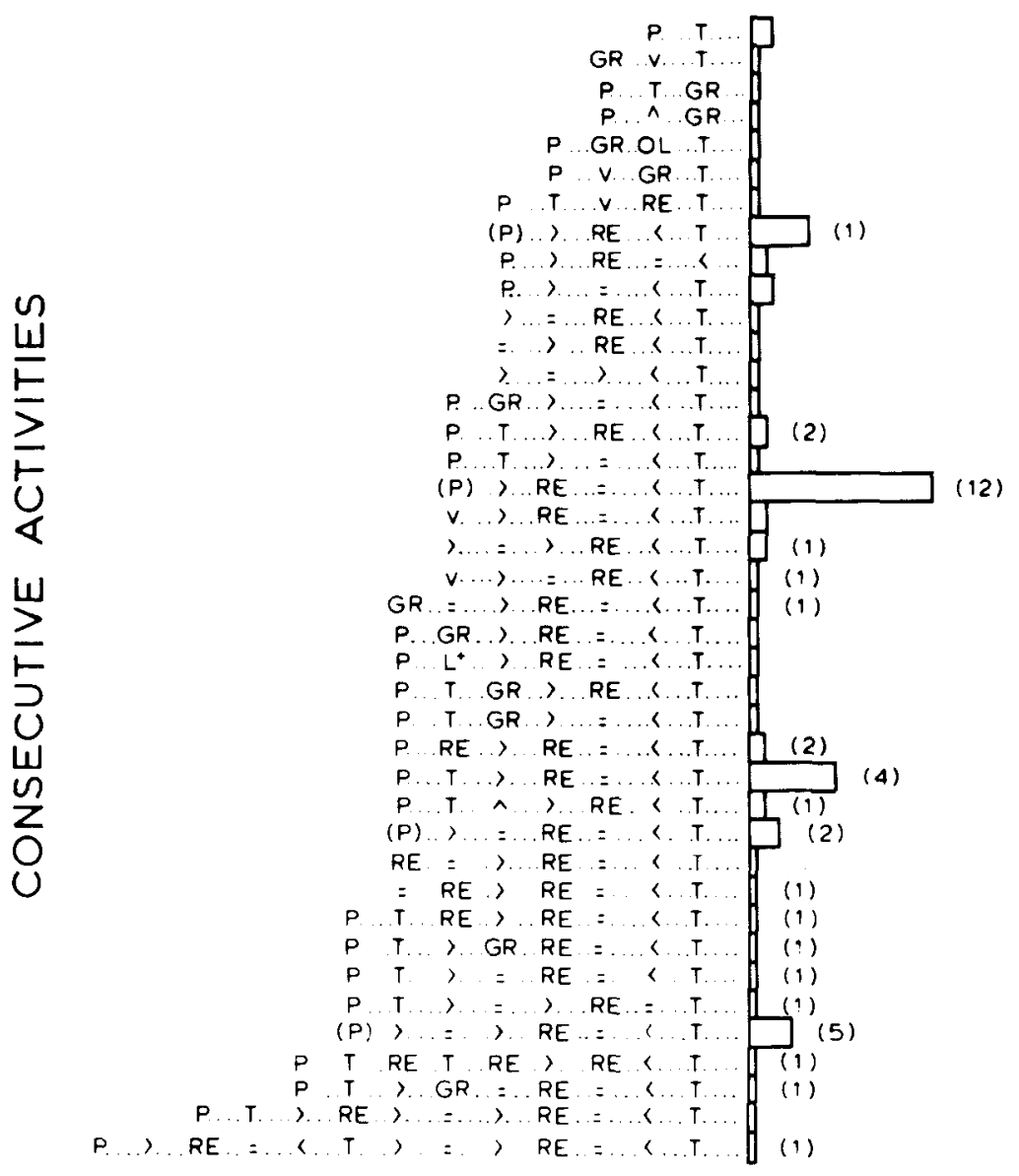

CORTICAL CONTROL 521C Sessions 57-60
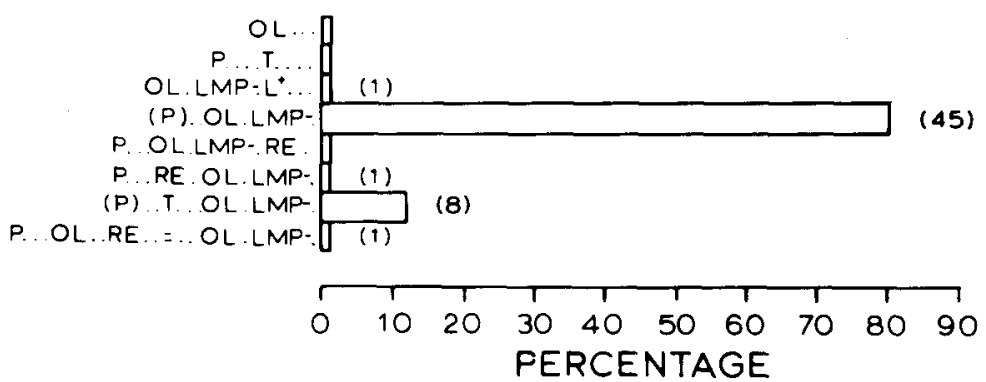

Figure 5 (opposite page and above). Summary of behavioral observations showing, to the left, consecutive activities (segments) preceding the pressing of the predictive lever and, to the right, frequency histograms. The frequency of each behavioral segment is expressed as a percentage of the total number of behavioral segments. Data are presented for the animal from each group with the largest number of trials (i.e., reinforcements) on the last four sessions of training. Figures in parentheses represent the number of times that particular behavioral segment resulted in reinforcement (see Appendix for key). 
ticular location and were spread over relatively long periods of time, whereas the lesioned groups engaged in larger numbers of briefer activities covering the whole box.

\section{DISCUSSION}

With training, neodecorticates, like the other groups, reduced the frequency of short interresponse times and increased the frequency of longer ones (Figure 3). They also had a highly significant correlation between increasing number of sessions and number of reinforcements obtained per session. Furthermore, the results from the interresponse time per opportunity analysis (Anger, 1956) clearly showed that, with training, the neodecorticates were increasingly more likely to respond in later bins, having the highest probability of responding in the four bins after reinforcement became available. These findings, taken together with those of Jaldow, Oakley, and Davey $(1989,1990)$, strongly suggest that neodecorticates retain their temporal sensitivity.

Richelle and Lejeune (1980) argue that the differential reinforcement of low-rate schedule places a considerable "inhibitory load" on an animal not to press the reinforcing lever before the time is up (i.e., it involves what Richelle and Lejeune call "active" inhibition). Evidence also exists that points to neodecorticates' stronger associative learning capacity (Goldstein \& Oakley, 1985; Oakley, 1979a). In particular, Eames and Oakley (1979) have shown that neodecorticates "have a greater than normal tendency to physically contact the predictive CS," the CS (conditioned stimulus) in their autoshaping experiments being the lighting up of a lever. One may infer from this that neodecorticates are "drawn" more strongly towards the predictive lever than are the controls and may for this reason find it more difficult to withhold responding for the required interresponse time. For the hippocampals, the results confirm previous work showing them to have generally shorter IRTs (O'Keefe \& Nadel, 1978; Richelle $\&$ Lejeune, 1980) and offer some support to the findings of Olton, Meck, and Church (1987) which showed an earlier "peak time" in fimbria-fornix lesioned rats. This may be related to impaired memory of the time of reinforcement (Meck, 1988) or attentional impairment to proprioceptive cues (Richelle \& Lejeune, 1980).

O'Keefe and Nadel (1978) advance another factor that could possibly explain the shorter IRTs in both hippocampals and neodecorticates. They argue that hippocampectomy in animals results in the loss of the ability to form "spatial maps" of the environment based on what they call the "locale" system, which can generate place hypotheses (e.g., "avoid/approach that area"). Hippocampectomized animals, however, retain the use of a "taxon" system which comprises both guidance (e.g., "go to the lit lever") and orientation (e.g., "turn right/left") hypotheses. Given that collateral activities facilitate performance on DRL (Laties, Weiss, \& Weiss, 1969), any strategy or, even better, combination of strategies that would take the animal away from the reinforcing lever would be expected to facilitate DRL performance. According to $O$ 'Keefe and Nadel, hippocampals can count on guidance and orientation (taxon) but not on place (locale) hypotheses, making it harder for them to bridge the interresponse time. Neodecortication in rats has been shown to abolish place learning as effectively as hippocampectomy (Whishaw \& Kolb, 1984). It is therefore of interest to observe (Figure 5) that, for both control groups, efficient performance (bridging the interresponse time) predominantly involved moving to the other side of the Skinner box, which may be construed as a place strategy, whereas hippocampals and neodecorticates appear to have made extensive use of a combination of guidance and orientation hypotheses. The results are therefore consistent with the view that both hippocampus and neocortex are necessary for place learning in rats (Kolb, Sutherland, \& Whishaw, 1983; Sutherland, Kolb, \& Whishaw, 1982; Whishaw \& Kolb, 1984; see also Eames \& Oakley, 1985).

Whereas both control groups at the end of training had more than half of all their successful responses preceded by exteroceptive signals associated with reinforcement, the lesioned groups had most of their successful responses preceded by interoceptive signals (pressing the contingent lever). This does not necessarily argue against a proprioceptive-attentional deficit in hippocampals, as these findings may simply reflect the increased tendency for the lesioned groups to respond before the required DRL time was up. Hence, it is much more likely for a successful IRT to have been preceded by a press than by a reinforcer. It remains possible, however, that, especially in neodecorticates, sensory deficits (Eames \& Oakley, 1985; Goldstein \& Oakley, 1987) may have forced the use of interoceptive signals.

Evidence exists showing that neodecorticates may suffer from attentional impairments that can be ameliorated by appropriate pretraining aimed at focusing the animals' attention onto the relevant stimulus (Oakley, 1979a, 1980). It may be, therefore, that anchoring the beginning of the countdown with the end of reinforcement (exteroceptive signal) or the last leverpress on the reinforcing lever (i.e., two possible time markers) was, in fact, disruptive of their performance. One clear timing source (either exteroceptive or interoceptive) might have facilitated neodecorticates' behavior on the DRL schedule.

In all, the results showed that neodecorticates can perform reasonably well on a DRL schedule. On some of the variables, neodecorticates showed patterns of behavior that were similar to those shown by hippocampals; on other variables, their patterns of behavior differed. This suggests that, apart from possible impaired place learning, the neocortex and hippocampus make separate contributions to observed behavior on the DRL schedule (see also Jaldow, Oakley, \& Davey, 1989). Temporal sensitivity appears to remain in both hippocampectomized and neodecorticated rats, although its full expression may be impaired by remaining sensory/motor deficits (see Jaldow, Oakley, \& Davey, 1989, 1990; Kolb \& Whishaw, 1981) 
and possibly a reduced repertoire of behavioral strategies from which to generate effective collateral activities.

\section{REFERENCES}

ANGER, D. (1956). The dependence of interresponse times upon the relative reinforcement of different interresponse times. Journal of Experimental Psychology, 52, 145-161.

Blackman, D. (1979). Operant conditioning: An experimental analysis of behaviour. London: Methuen.

Cohen, L., Holliday, M. (1983). Statistics for social scientists. London: Harper \& Row.

DAveY, G. (1981). Animal learning and conditioning. London: Macmillan.

EAMES, L., \& OAKLEY, D. A. (1979). Differential autoshaping to visual stimuli in neodecorticated rats. IRCS Medical Science, 7, 88.

EAmeS, L., \& OAKLEY, D. A. (1985). Neocortex, hippocampus and performance in Lashley's maze III. In B. E. Will, P. Schmidt, \& J. C. Dalrymple-Alford (Eds.), Brain plasticity learning and memory (Advances in Behavioural Biology, Vol. 28, pp. 373-381). New York: Plenum.

Goldstein, L. H., \& OAKLEY, D. A. (1985). Expected and actual behavioural capacity after diffuse reduction in cerebral cortex: A review and suggestions for rehabilitative techniques with the mentally handicapped and head injured. British Journal of Clinical Psychology, 24, 13-24.

Goldstein, L. H., \& OAKLEY, D. A. (1987). Visual discrimination in the absence of visual cortex. Behavioural Brain Research, 24, 181-193.

Howell, D. C. (1982). Statistical methods for psychology. Boston: Duxbury Press.

Jaldow, E. J., Oakley, D. A., \& Davey, G. C. L. (1989). Performance of decorticated rats on fixed interval and fixed time schedules. European Journal of Neuroscience, 1, 461-470.

Jaldow, E. J., Oakley, D. A., \& Davey, G. C. L. (1990). Performance on two fixed interval schedules in the absence of neocortex in rats. Behavioral Neuroscience, 104, 763-777.

Kolb, B., Sutherland, R. J., \& Whishaw, I. Q. (1983). A comparison of the contributions of the frontal and parietal association cortex to spatial localization in rats. Behavioral Neuroscience, 97, 13-27.

KolB, B., \& Whishaw, I. Q. (1981). Decortication of rats in infancy or adulthood produced comparable functional losses on learned and species-typical behaviors. Journal of Comparative \& Physiological Psychology, 95, 468-483.

Laties, V. G., Weiss, B., Clark, R. L., \& Reynolds, M. D. (1965). Overt "mediating"' behavior during temporally spaced responding. Journal of the Experimental Analysis of Behavior, 8, 107-116.

Laties, V. G., Weiss, B., W Weiss, A. B. (1969). Further observations on overt "mediating" behavior and the discrimination of time. Journal of the Experimental Analysis of Behavior, 12, 43-57.

MeCK, W. H. (1988). Hippocampal function is required for feedback control of an internal clock's criterion. Behavioral Neuroscience, 102, 54-60.

OAKLEY, D. A. (1979a). Cerebral cortex and adaptive behaviour. In D. A. Oakley \& H. C. Plotkin (Eds.), Brain, behaviour and evolution (pp. 154-188). London: Methuen.

OAKLEY, D. A. (1979b). Learning with food reward and shock avoidance in neodecorticate rats. Experimental Neurology, 63, 627-642.

OAKLEY, D. A. (1980). Improved instrumental learning in neodecorticate rats. Physiology \& Behavior, 24, 357-366.
O'KEEFE, J., \& NADEL, L. (1978). The hippocampus as a cognitive map. Oxford: Clarendon Press.

Olton, D. S. (1983). Memory functions and the hippocampus. In W. Seifert (Ed.), Neurobiology of the hippocampus (pp. 335-373). London: Academic Press.

Olton, D. S., Meck, W. H., \& Church, R. M. (1987). Separation of hippocampal and amygdaloid involvement in temporal memory dysfunctions. Brain Research, 404, 180-188.

Richelle, M., \& Lejeune, H. (1980). Time in animal behaviour. Oxford: Pergamon Press.

Sidman, M. (1955). Technique for assessing the effects of drugs on timing behavior. Science, 122, 925.

Sutherland, R. J., Kolb, B., \& Whishaw, I. Q. (1982). Spatial mapping: Definitive disruption by hippocampal or medial frontal cortical damage in the rat. Neuroscience Letters, 31, 271-276.

Terry, P., Herbert, B. A. , OAkley, D. A. (1989). Anomalous patterns of response learning and transfer in decorticate rats. Behavioural Brain Research, 33, 105-109.

Terry, P., OAKLey, D. A. (1990). The effects of cortical or hippocampal damage on behavioral flexibility in the rat. Psychobiology, 18, 404-415.

Whishaw, I. Q., \& KolB, B. (1984). Decortication abolishes place but not cue learning in rats. Behavioural Brain Research, 11, 123-134.

Whishaw, I. Q., Schallert, T., KolB, B. (1981). An analysis of feeding and sensorimotor abilities of rats after decortication. Journal of Comparative \& Physiological Psychology, 95, 85-103.

Zimmerman, J., a SChuster, C. R. (1962). Spaced responding in multiple DRL schedules. Journal of the Experimental Analysis of Behavior, 5, 497-504.

\section{APPENDIX}

Key to the Behavioral Observations

$$
\begin{aligned}
\mathrm{GR}= & \text { Grooming } \\
\mathrm{L}+= & \text { Making contact with but not pressing lit lever } \\
\mathrm{LMP}-= & \text { Gnawing, biting, grappling bulb cover over unlit } \\
& \text { (nonreinforcing) lever } \\
\mathrm{OL}= & \text { Pressing or making contact with other (unlit) } \\
& \text { lever } \\
\mathrm{P}= & \text { Pressing lit (reinforcing) lever } \\
\mathbf{R E}= & \text { Rearing } \\
\mathrm{T}= & \text { Tray entry (a following * indicates that the } \\
& \text { animal spent some time in the tray) } \\
>= & \text { Animal moving to right side of Skinner box } \\
& \text { (opposite to the tray) } \\
<= & \text { Animal moving to left side of Skinner box } \\
& \text { (tray side) } \\
\mathrm{v}= & \text { Animal facing forward (into observer's direction) } \\
= & \text { Animal facing away from observer } \\
== & \text { Gnawing, biting, sniffing meshed floor of } \\
& \text { Skinner box }
\end{aligned}
$$

Note-P and * sometimes occur in brackets, indicating that that particular segment did not always start with a press or involve the animal spending some time in the tray, respectively. Also note that P may indicate more than one press, provided they were not separated by another activity.

(Manuscript received November 13, 1989; revision accepted for publication April 12, 1990.) 